\title{
Pembuatan Elektrokardiogram dan Penentuan Interval QRS secara Otomatis
}

\author{
Aprilia Tri Astuti, ${ }^{*}$ Nuryani, ${ }^{\dagger}$ dan Anik Lestari \\ Jurusan Fisika, Fakultas Matematika dan Ilmu Pengetahuan Alam Universitas Sebelas Maret \\ Jl. Ir.Sutami No. 36 A Kentingan, Surakarta 57126
}

Intisari

Pada penelitian ini telah dibuat rancangan sistem elektrokardiogram (EKG) yang dilengkapi de-ngan sistem penentuan interval QRS secara otomatis. Sistem EKG yang dibuat menggunakan arduino dan komputer. Hasil dari penelitian ini diimplementasikan menggunakan perangkat lunak processing. Data sinyal jantung yang digunakan pada penelitian ini diambil langsung dari pasien. Untuk menentukan interval QRS maka terlebih dahulu dilakukan penentuan posisi puncak R. Posisi puncak R selanjutnya digunakan untuk menentukan posisi titik Q dan posisi titik S. Hasil akurasi penentuan interval QRS pada penelitian ini adalah sebesar 95,89\%.

\begin{abstract}
In this research, system design electrocardiogram (ECG) is equipped with a QRS interval determination system automatically. ECG systems was created using arduino and computer. The results of this research is implemented using software processing. Cardiac signal data used were taken from patients. To determine the QRS interval, the first is the determination of the peak position R. Peak position $\mathrm{R}$ is then used to determine the position of the point $\mathrm{Q}$ and the position of the point S. Result for accuracy determination QRS interval in this research is up to $95.89 \%$.
\end{abstract}

KATA KUNCI: Electrocardiogram, Interval QRS, Arduino, software processing http://dx.doi.org/10.12962/j24604682.v13i1.2129

\section{PENDAHULUAN}

Jantung merupakan organ terpenting pada tubuh manusia yang fungsi utamanya adalah memompa darah ke seluruh tubuh. Seperti organ tubuh lainnya, jantung juga dapat diserang oleh berbagai penyakit. Penyakit jantung merupakan penyakit yang membahayakan dan menjadi penyebab utama kematian [1]. Klasifikasi sinyal jantung diperlukan untuk mengetahui penyakit jantung yang seringkali datang secara tiba-tiba. Kondisi jantung dapat diketahui melalui aktivitas listrik jantung yang direpresentasikan dalam bentuk grafik menggunakan sebuah instrumen medis yang disebut elektrokardiogram (EKG) [2]. Jantung merupakan organ yang mampu memproduksi muatan listrik. Karena tubuh adalah konduktor yang baik, maka impuls yang dihasilkan jantung dapat menjalar ke seluruh tubuh, sehingga potensial aksi yang dipancarkan oleh jantung dapat diukur melalui elektroda-elektroda yang diletakkan pada berbagai posisi di permukaan tubuh [3]. Informasi pengukuran EKG diambil oleh elektroda yang ditempatkan di lokasi yang ditunjuk pada tubuh. Ini adalah cara terbaik untuk mengukur dan mendiagnosis irama abnormal jantung, irama abnormal jantung disebabkan oleh kerusakan jaringan konduktif yang membawa sinyal listrik atau disebabkan oleh ketidakseimbangan elek-

\footnotetext{
*E-MAIL: aprilialiolio@yahoo.com

${ }^{\dagger}$ E-MAIL: nuryani@mipa.uns.ac.id
}

trolit [4]. Menurut polaritasnya, elektroda-elektroda EKG dapat dibagi menjadi elektroda positif (anoda), negatif (katoda) dan netral (ground electrode) [5]. Fungsi dasar dari elektroda adalah mendeteksi sinyal kelistrikan jantung yaitu ion-ion yang berjalan pada seluruh tubuh sesuai pergerakan darah oleh jantung. Cara kerja transducer ini adalah untuk mengkonversi informasi biologis menjadi sinyal elektrik yang dapat diukur [6].

Aktivitas listrik jantung disebabkan oleh irama depolarisasi dan repolarisasi otot jantung. Bagian dalam jantung yang berperan dalam sistem konduksi listrik jantung adalah Sinoatrium Node (SA Node), Atrioventricular Node (AV Node), Berkas His dan Serabut Purkinje [7]. Aktivitas listrik jantung kemudian ditampilkan dalam bentuk gelombang oleh EKG. Gelombang EKG terdiri dari 5 komponen gelombang yang berbeda, yaitu gelombang P, Q, R, S dan T [8]. Satu gelombang EKG terdiri atas sebuah gelombang $P$ yang terjadi akibat depolarisasi otot atrium, gelombang QRS yang terjadi akibat depolarisasi otot ventrikel dan gelombang T yang terjadi akibat repolarisasi otot ventrikel. Kinerja sistem klasifikasi EKG bergantung pada keakuratan dari pengukuran gelombang $\mathrm{P}$, kompleks QRS serta gelombang T. Oleh sebab itu, penentuan parameter gelombang EKG atau bisa disebut ECG delineation menjadi sangat penting dalam melakukan diagnosa jantung menggunakan EKG [9].

Klasifikasi gelombang EKG yang menjelaskan jangka waktu dan interval dari bagian-bagian gelombang serta amplitudo dari puncak ke puncak gelombang mengungkapkan informasi klinis yang signifikan untuk diagnosis jantung [10]. 

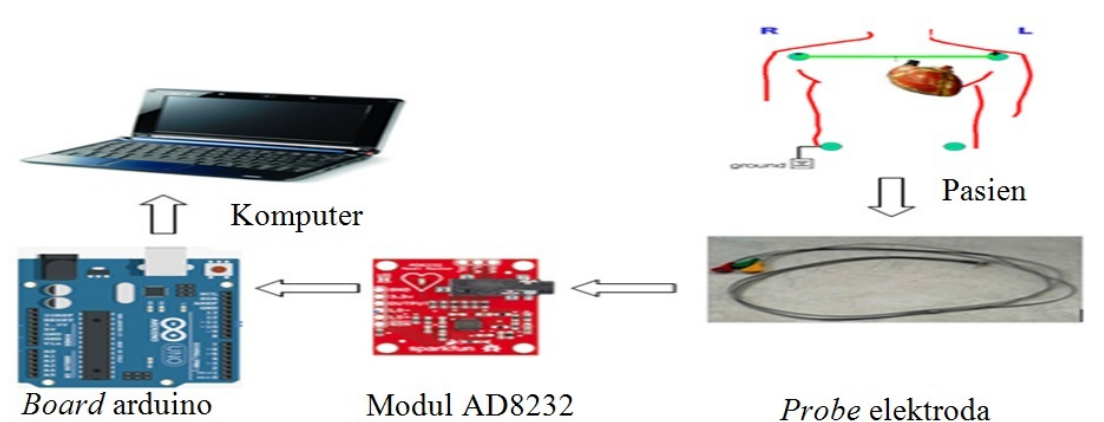

Probe elektroda

Gambar 1: Skema alat EKG.

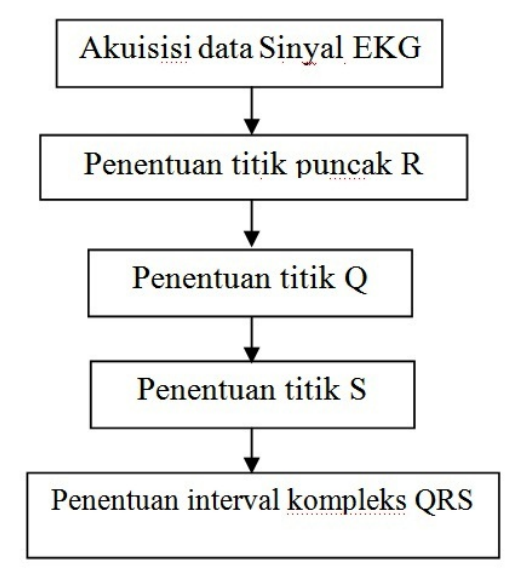

Gambar 2: Skema umum penelitian.

Pembacaan grafik EKG secara manual tidak dapat langsung digunakan untuk mendiagnosis kondisi jantung, oleh sebab itu perlu adanya sistem otomatisasi dalam menganalisis grafik EKG. Dalam era digital ini, digitalisasi EKG perlu dilakukan untuk proses analisis sinyal EKG. Hal tersebut yang melatarbelakangi penelitian ini dalam merancang sistem analisis EKG secara otomatis berbasis komputer.

Pada penelitian ini akan dilakukan pembuatan sistem EKG yang dilengkapi dengan sistem untuk menentukan interval QRS secara otomatis berbasis komputer. Hasil dari penelitian ini diimplementasikan menggunakan perangkat lunak processing. Processing merupakan bahasa pemrograman yang sering digunakan pada teknik komputasi. Processing mengaitkan konsep software pada prinsip-prinsip bentuk rupa, gerak, dan interaksi [11].

\section{METODE PENELITIAN}

Perangkat keras untuk perancangan sistem EKG pada penelitian ini tersusun dari probe elektroda, modul AD8232, board arduino dan seperangkat komputer. Skema alat ditunjukkan pada Gambar 1.

Skema umum penelitian ditunjukkan pada Gambar 2. Setelah data didapat dari proses akuisisi data, langkah selanjut-
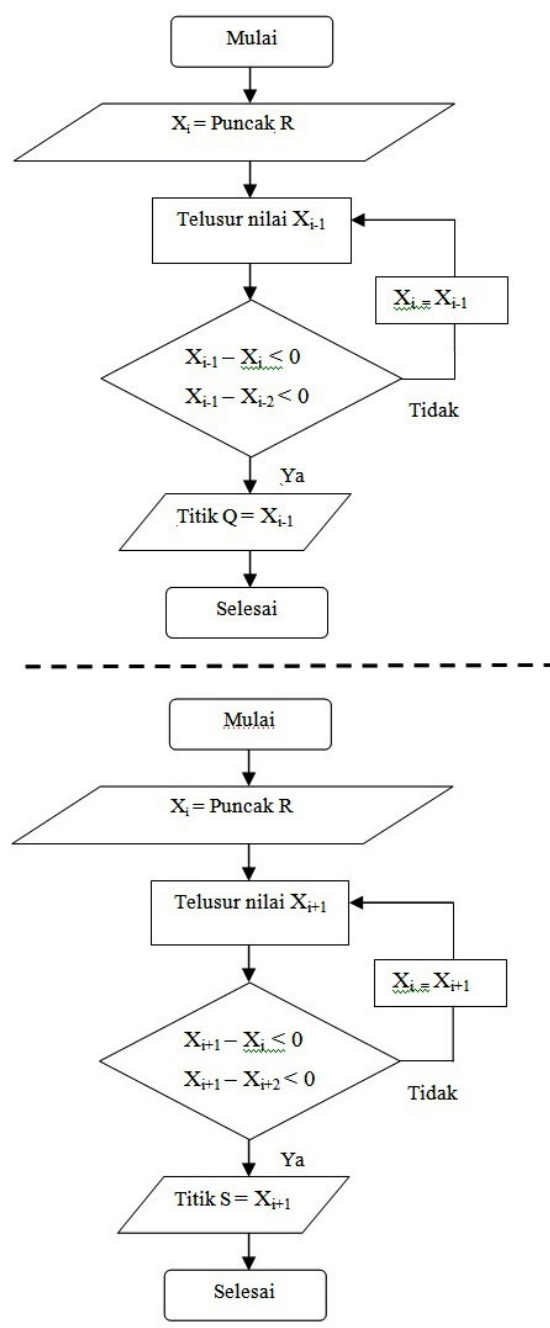

Gambar 3: Tahap penentuan titik Q dan titik S.

nya adalah menentukan titik puncak $\mathrm{R}$ dengan menggunakan garis threshold. Nilai posisi puncak R tersebut selanjutnya digunakan untuk mencari interval RR serta nilai posisi titik Q dan nilai posisi titik S. Interval kompleks QRS didapat dengan mengurangkan nilai pada posisi titik $S$ dan nilai pada posisi titik Q. Tahap penentuan titik Q dan $\mathrm{S}$ ditunjukkan pada 


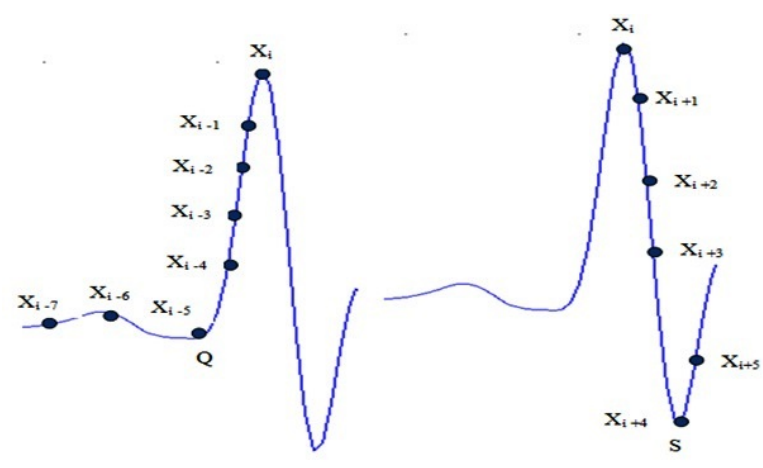

Gambar 4: Telusur data untuk menentukan titik Q dan titik S.

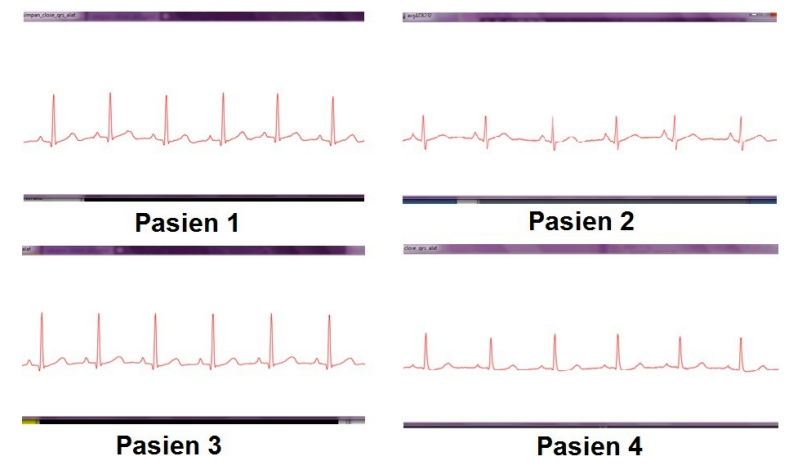

Gambar 5: Hasil sinyal EKG pasien.

Gambar 3.

Penentuan interval QRS pada penelitian ini dilakukan tiap segmen, yang dalam satu segmennya terdiri dari 360 data. Penentuan posisi titik $\mathrm{Q}$ dan posisi titik $\mathrm{S}$ dilakukan dengan penelusuran data. Tiap data dikurangkan dengan data sebelumnya dan data setelahnya, apabila hasil keduanya bernilai negatif maka data tersebut didefinisikan sebagai titik $\mathrm{Q}$ atau titik S. Yang membedakan antara titik Q dan titik S disini adalah titik $\mathrm{Q}$ berada sebelum puncak $\mathrm{R}$ sedangkan titik $\mathrm{S}$ berada setelah puncak R. Sehingga data yang ditelusur untuk menentukan titik $\mathrm{Q}$ adalah data dari sebelum puncak $\mathrm{R}$ menuju data awal segmen. Sedangkan data yang ditelusur untuk menentukan titik $\mathrm{S}$ adalah data dari setelah puncak $\mathrm{R}$ menuju data akhir segmen. Penelusuran data untuk menentukan titik Q dan S ditunjukkan pada Gambar 4.

\section{HASIL DAN PEMBAHASAN}

Gambaran sinyal EKG yang didapat dari pasien ditunjukkan pada Gambar 5. Pada gambar sinyal keempat pasien sudah tampak adanya gelombang $\mathrm{P}, \mathrm{Q}, \mathrm{R}, \mathrm{S}$ dan T. Keempat gelombang tersebut adalah representasi dari aktivitas jantung yang merupakan komponen-komponen dari satu gelombang EKG. Dari hasil tersebut maka dapat dikatakan bahwa sistem sudah dapat mendeteksi aktivitas jantung pasien dengan baik. Hasil akurasi dari penelitian ini didapat dengan memband- ingkan nilai interval QRS dari program yang dibuat dengan

TABEL I: Nilai Interval QRS.

\begin{tabular}{ccccc}
\hline \hline Pasien & QRS Manual (s) & QRS Program (s) \\
\hline 1 & 0.053 & 0.008 & 0.059 & 0.040 \\
2 & 0.054 & 0.007 & 0.056 & 0.020 \\
3 & 0.056 & 0.010 & 0.058 & 0.030 \\
4 & 0.059 & 0.013 & 0.070 & 0.053 \\
\hline \hline
\end{tabular}

nilai interval QRS yang didapat dari perhitungan manual. Nilai interval QRS hasil program dan hasil manual dari kedua pasien dapat dilihat pada Tabel I.

Pada pasien pertama, terdapat 92 nilai interval QRS yang dihasilkan. Dari 92 nilai itu terdapat 5 nilai yang berbeda saat dibandingkan dengan hasil perhitungan manual. Sedangkan pada pasien dua, terdapat 69 nilai interval QRS yang dihasilkan. Dari 69 nilai itu terdapat 2 nilai yang berbeda saat dibandingkan dengan hasil perhitungan manual. Pasien 3 terdapat 88 nilai interval QRS yang dihasilkan, dimana terdapat 2 nilai interval QRS yang berbeda nilainya dengan hasil perhitungan manual. Pada pasien 4 terdapat 92 nilai interval QRS dengan 5 nilai interval QRS yang berbeda saat dibandingkan dengan hasil manual. Dari nilai yang dihasilkan, didapat akurasi dari setiap pasien. Akurasi pasien pertama adalah sebesar $94,56 \%$, pasien kedua $97,10 \%$, pasien ketiga $97,70 \%$ dan pasien keempat $94,56 \%$. Pasien 1 dan 4 mempunyai akurasi yang sama besar yaitu $94,56 \%$, namun hasil nilai interval QRS nya berbeda. Hal tersebut dikarenakan pasien 1 dan 4 menghasilkan jumlah interval QRS yang sama dengan jumlah kesalahan yang juga sama yaitu terdapat 5 kesalahan nilai dari 92 nilai interval QRS yang dihasilkan. Perbedaan nilai interval QRS nya disebabkan karena data nilai EKG jantung kedua pasien berbeda, sehingga walaupun akurasi sama namun nilai interval QRS nya berbeda. Kondisi jantung yang normal memiliki lebar interval QRS dalam kisaran 0,06 sampai 0,1 sekon. Sehingga dari hasil yang didapatkan penenlitian ini, keempat pasien termasuk dalam kategori kondisi jantung yang normal.

\section{SIMPULAN}

Pada penelitian ini telah dibuat sistem elektrokardiogram yang dilengkapi dengan sistem penentuan interval QRS secara otomatis berbasis komputer yang diimplementasikan mengunakan perangkat lunak processing. Lebar interval QRS merupakan selisih dari nilai posisi titik $\mathrm{S}$ dengan nilai posisi titik Q. Nilai interval QRS pasien pertama adalah sebesar $0,059 \pm$ 0,040 sekon, pasien kedua adalah $0,056 \pm 0,020$ sekon, pasien ketiga $0,058 \pm 0,030$ sekon dan pasien keempat adalah sebesar $0,070 \pm 0,053$ sekon. Kondisi jantung keempat pasien termasuk dalam kategori normal. Akurasi total dari penelitian ini adalah sebesar 95,89\%. 
[1] I. Soeharto, Serangan Jantung dan Stroke (Penerbit PT. Gramedia Pustaka Utama, Jakarta, 2004).

[2] J.P. De Vos, and M.M. Blanckenbrg, IEEE Transactions on Biomedical Engineering, 54, 244-252 (2007).

[3] S. Maisyaroh, Rancang Bangun InstrumentasiI Elektrokardiografi Berbasis PC Menggunakan Sound Card, Skripsi, UNIMED, Medan, 2012.

[4] E. Braunwald, Heart Disease: A Textbook of Cardiovascular Medicine (Fifth Edition. Philadelphia, W.B. Saunders Co., 1997).

[5] A.N. Azhar, dan Suyanto, Studi Identifikasi Sinyal ECG Irama Myocardial Ischemia Dengan Pendekatan Fuzzy Logic, Jurusan Teknik Fisika Fakultas Teknik ITS, 7(4), 193-206 (2009).

[6] Manihuruk dan S.D. Alexander, Rancangan Akuisisi Data Frekuensi Detak Jantung Berbasis Mikrokontroler AT89S51 Se- bagai Pengukur Denyut Jantung Dengan display LCD, Universitas Sumatera Utara, Medan, 2010.

[7] P. Waskito, R. Hasanah, A. Rika, D.T. Yunita, Biolistrik elektrokardiogram, Universitas Tanjung Pura, Pontianak, 2013.

[8] Milhorn and H. Thomas,Electrocardiography for the Family Physician: The Essentials (BrownWalker Press Boca Raton. Florida USA, 2005).

[9] A. Surtono, T.S. Widodo, M. Tjokronagoro, Analisis Klasifikasi Sinyal EKG Berbasis Wavelet dan Jaringan Syaraf Tiruan, Universitas Lampung, Lampung, 2012.

[10] L. Schamroth, An Introduction to Electrocardiography (seventh ed.,Wiley. India, 2009).

[11] R. Fikri, I.F. Adam, I. Prakoso, Dasar-Dasar Pemrograman (Andi, Jogjakarta, 2005). 